\title{
Significance of Pseudomonas aeruginosa in Sputum
}

\author{
M. W. BURNS
}

\section{Summary}

Pseudomonas aeruginosa was isolated from the sputum of 63 patients. In 34 the organism was a commensal, in 14 it was causing chronic suppuration, and in 10 had interfered with antibiotics directed against other organisms and was thus indirectly pathogenic. In five patients, all of whom died, the organism could have been acting as an acute pathogen. Attempts should be made to determine the nature of the organism's pathogenicity in a given patient and appropriate therapy withheld or administered accordingly.

\section{Introduction}

Pseudomonas aeruginosa is being isolated with increasing frequency from the respiratory tract (Finland et al., 1959). Though the organism does not always produce disease there (Williams et al., 1960) its presence is potentially serious because of the resistance of pseudomonas to most antibiotics, and those that might be effective can have harmful side effects. It was the aim of this study to attempt an assessment of the pathogenic role of $P$. aeruginosa in individual subjects as a guide to management.

\section{Material and Methods}

All patients who produced pseudomonas in sputum over a three-year period (1968-70) in the 100-bed Cameron Wing cardiothoracic unit of St. Vincent's Hospital, Sydney, were the subjects of the investigation. All were adults or older children. Serum was examined where possible for the presence of specific precipitins to pseudomonas (Burns and May, 1968; Burns, 1972). Two types of antibacterial therapy for $P$. aeruginosa were used. Aerosol colistin sulphomethate sodium $150 \mathrm{mg}$ or gentamicin $20 \mathrm{mg}$ three times daily by means of a Bennett respirator (model TV-2P) was used for mere suppression. Eradication of pseudomonas was attempted with intravenous carbenicillin $30 \mathrm{~g}$ daily ( $5 \mathrm{~g}$ four-hourly) and gentamicin, eighthourly, in maximal dosage (Gingell and Waterworth, 1968) given separately by bolus injection, together with colistin aerosol three times daily.

\section{Results}

$P$. aeruginosa was isolated from the sputum of 63 patients (see table). In 34 the organism was a commensal-that is, patients exhibited no evidence of disease caused by it or it disappeared without specific therapy. In 10 , seven with chronic bronchitis, two with crushed chest injuries, and one with a post-thoracotomy respiratory infection, it was acting as an "indirect pathogen" (Maddocks and May, 1969). That is, it interfered with antibiotic therapy directed against other organisms such as Haemophilus

Garvan Institute of Medical Research, St. Vincent's Hospital, Sydney, Australia

M. W. BURNS, PH.D., F.R.A.C.P., Physician and Senior Research Fellow

influenzae presumably by degradation of the drug. Aerosol antibacterial therapy appeared to eliminate the pseudomonas from the sputum without significant alteration in purulence or the patients' symptoms. Systemic agents such as ampicillin which were previously ineffective now eliminated the pus and symptoms of disease. The pseudomonas was of the common or rough variety and serum examination when performed showed no precipitins to it.

In 14 patients the pseudomonas was causing chronic infection. Each patient had chronic bronchial suppuration and nine of 12 tested showed specific precipitins to pseudomonas in the serum. The organism isolated from 10 patients in this group was the slimy or mucoid form of $P$. aeruginosa (Burns and May, 1968; Doggett and Harrison, 1969). Eight had bronchiectasis, two cystic fibrosis, and the others healed, cavitated tuberculosis, a mycetoma, chronic upper lobe pneumonia, and a bronchial carcinoma. Six patients died. Attempted suppression of the pseudomonas by inhalation therapy was unsuccessful in alleviating symptoms or in effectively reducing the bacterial population. Systemic eradication therapy was attempted in eight patients. In each one complete suppression of the organism was achieved in five to six days but, in every patient except one, the organism returned soon after suspension of therapy even if treatment had been given for as long as four weeks. In the patient who was cured, resection of bronchiectatic segments after the organism was suppressed was not followed by a relapse of infection.

Pseudomonas aeruginosa in Sputum of 63 Patients. Numbers in Parentheses refer to Patients with Tracheostomies

\begin{tabular}{|c|c|c|c|c|c|c|}
\hline \multirow{2}{*}{\multicolumn{3}{|c|}{ Pathogenic Role }} & \multirow{2}{*}{ No. of Patients } & \multicolumn{2}{|c|}{ Pseudomonas } & \multirow{2}{*}{ Deaths Recorded } \\
\hline & & & & Rough & Mucoid & \\
\hline $\begin{array}{l}\text { Commensal } \\
\text { Indirect } \quad \ldots \\
\text { Chronic } \quad \ldots \\
\text { Acute } \quad \ldots\end{array}$ & $\begin{array}{l}\because \\
\because \\
\because\end{array}$ & $\begin{array}{l}. \\
\because \\
\ddot{x}\end{array}$ & $\begin{aligned} 34 & (5) \\
10 & (2) \\
14 & (0) \\
5 & (3)\end{aligned}$ & $\begin{array}{r}34 \\
10 \\
4 \\
5\end{array}$ & $\begin{array}{r}0 \\
0 \\
10 \\
0\end{array}$ & $\begin{array}{l}0 \\
\times \\
0 \\
6 \\
5\end{array}$ \\
\hline Tot & & & $63(10)$ & 53 & 10 & 11 \\
\hline
\end{tabular}

In five patients, all of whom died, the organism could have been acting as an acute pathogen. Two developed postthoracotomy chest infections with pseudomonas in the sputum and died fairly quickly. One of the two had widespread radiological pulmonary opacification and, terminally, the organism was grown from blood cultures. Two had acute lung abscesses, possibly secondarily infected with pseudomonas, and died of haemorrhage. The fifth had an acute exacerbation of chronic bronchitis and died in respiratory failure. The pseudomonas in his sputum showed no sign of suppression by colistin aerosol.

The proportion of patients with tracheostomies in the first three groups was too low for the presence of a tracheostomy to be itself a significant cause of pseudomonas colonization or of death in these subjects. However, two of the three tracheostomy patients who died with presumed acute infections, including the man with positive blood cultures, became colonized with pseudomonas after the tracheostomy was performed, and this procedure may therefore have been a factor in the pathogenesis of the infection.

\section{Discussion}

These observations show that $P$. aeruginosa was behaving in four 
possible ways in the bronchial tree. Commonest was its role as a commensal, a non-pathogen. This was often obvious though sometimes retrospectively. Chronic suppuration was the next in frequency in this group of patients. Such infection was virtually impossible to eradicate but temporary suppression of the organism was readily achieved by systemic therapy. The third group exhibited the phenomenon of superinfection with "indirect pathogenicity" or antibiotic degradation by pseudomonas. In the fourth group at least one person was infected acutely by $P$. aeruginosa. In this type of patient it is assumed that lowered tissue resistance enables rough pseudomonas strains which have normally a low virulence for the respiratory tract to become invasive. Possibly a change to the mucoid variety might occur if the host survived long enough.

How can these observations be applied to individual patients? Pseudomonas has an intestinal habitat and can reach the pharynx through inspired air by infected droplets (Williams et al., 1960; Shooter et al., 1966). Presumably it can also ascend by the oesophagus. Antibacterial therapy which suppresses other organisms can lead to enhanced multiplication of pseudomonas in the mouth and pharynx and thus it appears in sputum en passant. From the pharynx it can of course spread to the bronchi. Therefore, in patients who are not seriously ill-for example, with acute or chronic bronchitis-its presence in sputum can be virtually ignored. Serum precipitin surveys (Burns and May, 1968; Burns, 1968, 1972) showing the rarity of antibody to pseudomonas in such patients tend to confirm the lack of pathogenicity of this organism in these disorders. If there is an indication to treat the underlying infection, the impression gained from using common antibiotics is that tetracycline is less likely to be interfered with by pseudomonas than is ampicillin or co-trimoxazole. If such an infection, again in a patient who is not seriously ill, fails to respond to this type of therapy, then inhalation treatment should be added to the existing therapy. The use of colistin inhalation therapy has been reported by May (1968). Degradation of ampicillin in patients by pseudomonas was found by Maddocks and May (1969) and Davies (1971) described invitro enzymic destruction of aminoglycosides by this organism, but no such phenomenon has been described for co-trimoxazole. If interference with co-trimoxazole is confirmed, it is interesting to speculate whether enzymic degradation or some other mechanism would be responsible. At this stage, inquiries should be made concerning the colonial morphology of the pseudomonas, which will usually be the rough form. Precipitin studies, easily performed in agar gel using crude ultrasonic extracts of the organism (Burns, 1972), can here be valuable.

If the patient has a history of long-standing bronchial suppuration, the chest radiographic appearance is consistent with bronchiectasis, cystic fibrosis etc., the organism is the mucoid variety, and the serum shows specific precipitins to pseudomonas, then one is faced with a true chronic infection. A decision should be made whether antibiotic therapy is best discontinued. Bronchography should if possible be performed in the hope that the suppurative disease is localized and that surgery is feasible. Removal of this disease removes the tissue susceptible to true pseudomonas infection and the residual, possibly bronchitic, bronchi are no more susceptible to further such infection than are those of straight-forward bronchitic subjects. If surgery is contemplated, preoperative systemic antipseudomonas therapy can be given, combined with an appropriate aerosol antibiotic. Though aerosol therapy alone was not effective in suppressing pseudomonas in chronically infected patients in this study, some authors (Boxerbaum et al., 1971) have observed otherwise-at least in cystic fibrosis. Thus, until further observations are recorded, it can be combined with systemic therapy in the hope of enhancing the effects of the latter. Similarly, in acute exacerbations of chronic suppurative infection with $P$. aeruginosa, which occur just as they do with $H$. influenzae in bronchitis, systemic treatment probably with aerosol therapy would be indicated as a temporary measure. This is particularly so in acute respiratory failure in a patient with minimally deranged blood gas levels in remission.

The significance of the mucoid form of pseudomonas as a cause of suppuration, and not merely as a passenger in the respiratory tract, needs to be emphasized. Such strains are actually capsulated (Sonnenschein, 1927) but it is not clear whether the capsular material is comparable with that of pneumococci and klebsiellae and many authors refer to it as slime (Liu et al., 1961; Liu and Mercer, 1963; Callaghan et al., 1964; Brown and Lowbury, 1965). Though mucoid strains of $P$. aeruginosa are rare in nature (Doggett et al., 1966), the ability to produce slime is a characteristic of the species (Haynes, 1951) and, under suitable conditions in vitro-for example, growing in glucose broth - can be found in virtually every strain (Haynes, 1951 ; Brown and Lowbury, 1965). It is interesting to speculate whether conditions in the bronchial tree can sometimes be suitable for inducing slime production by a hitherto "rough" type of organism and whether such a change is accompanied by the acquisition of potential virulence. Doggett and his coworkers have studied this organism in great detail, particularly in patients with cystic fibrosis (Doggett et al., 1964, 1965, 1966; Doggett and Harrison, 1969).

In the last group in the present study-that is, patients who are seriously ill with pseudomonas in the sputum and death is feared-systemic therapy should be started before it is too late. This is especially the case if widespread radiographic pulmonary opacification is seen. Only experience will determine what is the correct approach to this situation.

Thanks are due to Miss S. Abrahams for technical help, and to Mrs. L. Fernandes for bacteriological laboratory work; to Dr. L. Lazarus, Dr. D. Bryant, and Mrs. L. Devitt for their advice; and to Mrs. D. Newton for typing the manuscript.

The study was supported by a part-time research grant of the Royal Australasian College of Physicians and a grant-in-aid from the Asthma Foundation of New South Wales.

\section{References}

Boxerbaum, B., Pittman, S., Doershuk, C. F., Stern, R. C., and Matthews, L. W. (1971). Fournal of Infectious Diseases, 124, Suppl., p. 293. Brown, V. I., and Lowbury, E. J. L. (1965). Fournal of Clinical Pathology, $18,752$.

Burns, M. W. (1968). Australasian Annals of Medicine, 17, 289.

Burns, M. W. (1972). Medical Fournal of Australia, 2, 697.

Burns, M. W., and May, J. R. (1968). Lancet, 1, 270.

88, 805. S., Beyerlein, B., and Mull, J. D. (1964). Fournal of Bacteriology, Davies, J. (1971). Fournal of Infectious Diseases, 124, Suppl., p. 7. Doggett, R. G., Harrison, G. M., and Wallis, E. S. (1964). Fournal of
Bacteriology, 87, 427. Doggett, R. G., Harrison, G. M., Stillwell, R. N., and Wallis, E. S. (1965).
fournal of Bacteriology, 89, 476.

Doggett, R. G., Harrison, G. M., Stillwell, R. N., and Wallis, E. S. (1966).

International Cystic Fibrosis G. M. (1969). In Proceedings of the 5th International Cystic Fibrosis Conference, ed. D. Lawson, p. 175. London,

Finland, M. Jones, W. F and Trust.

Medical Association., and Barnes, M. W. (1959). Fournal of the American

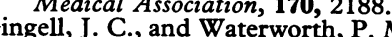

Gingell, J. C., and Waterworth, P. M. (1968). British Medical Fournal, 2, 19. Haynes, W. C. (1951). Fournal of General Microbiology, 5, 939. iu, P. V., Abe, Y., and Bates, J. L. (1961). Fournal of Infectious Diseases, 108,218

Liu, P. V., and Mercer, C. B. (1963). Fournal of Hygiene, 61, 485.

Maddocks, J. L., and May, J. R. (1969), Lancet, 1, 793.

May, J. R. (1968). Chemotherapy of Chronic Bronchitis and Allied Disorders, pp. 16, 71, 74. London, English Universities Press.

Shooter, R. A., et al. (1966). Lancet, 2, 1331.

Sonnenschein, C. (1927). Zentralblatt für Bakteriologie, Parasitenkunde, Infektionskrankheiten und Hygiene, I Abt., 104, 365

Williams, R., Williams, E. D., and Hyams, D. E. (1960). Lancet, 1, 376. 